\title{
Biological responses according to the shape and size of carbon nanotubes in BEAS-2B and MESO-I cells
}

This article was published in the following Dove Press journal:

International Journal of Nanomedicine

17 April 2014

Number of times this article has been viewed

\author{
Hisao Haniu ${ }^{1,2}$ \\ Naoto Saito ${ }^{2,3}$ \\ Yoshikazu Matsuda ${ }^{4}$ \\ Tamotsu Tsukahara ${ }^{5}$ \\ Yuki Usui 1,6,7 \\ Kayo Maruyama ${ }^{2,3}$ \\ Seiji Takanashi' \\ Kaoru Aoki' \\ Shinsuke Kobayashi' \\ Hiroki Nomura' \\ Manabu Tanaka' \\ Masanori Okamoto' \\ Hiroyuki Kato' \\ 'Department of Orthopaedic \\ Surgery, Shinshu University \\ School of Medicine, Nagano, Japan; \\ ${ }^{2}$ Insutitute for Biomedical Sciences, \\ Shinshu University, Nagano, Japan; \\ ${ }^{3}$ Department of Applied Physical \\ Therapy, Shinshu University School \\ of Health Sciences, Nagano, Japan; \\ ${ }^{4}$ Clinical Pharmacology Educational \\ Center, Nihon Pharmaceutical \\ University, Saitama, Japan; \\ ${ }^{5}$ Department of Hematology and \\ Immunology, Kanazawa Medical \\ University, Ishikawa, Japan; ${ }^{6}$ Research \\ Center for Exotic Nanocarbons, \\ Shinshu University, Nagano, Japan; \\ ${ }^{7}$ Aizawa Hospital, Sports Medicine \\ Center, Nagano, Japan
}

Correspondence: Hisao Haniu Insutitute for Biomedical Sciences, Shinshu University, 3-I-I Asahi, Matsumoto, Nagano 390-862I, Japan

$\mathrm{Tel}+8 \mathrm{I} 263372659$

Fax +8I 263358844

Email hhaniu@shinshu-u.ac.jp

\begin{abstract}
This study aimed to investigate the influence of the shape and size of multi-walled carbon nanotubes (MWCNTs) and cup-stacked carbon nanotubes (CSCNTs) on biological responses in vitro. Three types of MWCNTs $-\mathrm{VGCF}^{\circledR}-\mathrm{X}, \mathrm{VGCF}^{\circledR}-\mathrm{S}$, and $\mathrm{VGCF}^{\circledR}$ (vapor grown carbon fibers; with diameters of 15,80 , and $150 \mathrm{~nm}$, respectively) - and three CSCNTs of different lengths (CS-L, 20-80 $\mu \mathrm{m}$; CS-S, 0.5-20 $\mu \mathrm{m}$; and CS-M, of intermediate length) were tested. Human bronchial epithelial (BEAS-2B) and malignant pleural mesothelioma cells were exposed to the CNTs $(1-50 \mu \mathrm{g} / \mathrm{mL})$, and cell viability, permeability, uptake, total reactive oxygen species/superoxide production, and intracellular acidity were measured. CSCNTs were less toxic than MWCNTs in both cell types over a 24-hour exposure period. The cytotoxicity of endocytosed MWCNTs varied according to cell type/size, while that of CSCNTs depended on tube length irrespective of cell type. CNT diameter and length influenced cell aggregation and injury extent. Intracellular acidity increased independently of lysosomal activity along with the number of vacuoles in BEAS-2B cells exposed for 24 hours to either CNT (concentration, $10 \mu \mathrm{g} / \mathrm{mL}$ ). However, total reactive oxygen species/superoxide generation did not contribute to cytotoxicity. The results demonstrate that CSCNTs could be suitable for biological applications and that CNT shape and size can have differential effects depending on cell type, which can be exploited in the development of highly specialized, biocompatible CNTs.
\end{abstract}

Keywords: multi-walled carbon nanotube, cup-stacked carbon nanotube, cytotoxicity, in vitro, intracellular acidity

\section{Introduction}

Due to their unique physicochemical properties, carbon nanotubes (CNTs) have applications in a wide variety of industries. One major area of application is in the manufacture of biomaterials and devices, which include biosensors and drug and vaccine delivery vehicles. ${ }^{1,2}$ CNTs have the advantage of superior mechanical strength, and carbon materials in general are considered inert and therefore biocompatible. . $^{3,4}$ However, before CNTs can be incorporated into new and existing biomedical devices, their toxicity and biocompatibility need to be thoroughly investigated. Mice injected intraperitoneally with CNTs exhibited toxicological changes similar to those induced by exposure to asbestos, ${ }^{5,6}$ and CNTs have been linked to the induction of mesotheliomas. ${ }^{7,8}$ Although some in vivo studies have been conducted on the safety of CNT exposure by inhalation or intratracheal administration, their findings have been indeterminate. ${ }^{9-13}$ Results from in vitro studies have also been ambiguous, with some studies reporting that CNTs induce cytotoxicity and cytokine production, ${ }^{14-18}$ and others showing that no significant biological responses are elicited. ${ }^{19,20}$ 
Many reasons have been proposed for these contradictory findings. First, CNTs can be single-walled, multi-walled (MWCNTs), as well as cup-stacked (CSCNTs), and can differ in terms of length and diameter as well as physiochemical properties such as shape, agglomeration, surface structure, and carbon defects, any of which can influence the toxicological evaluation. ${ }^{21-27}$ Moreover, impurities in CNTs have been shown to induce oxidative stress, resulting in cellular damage. ${ }^{28,29}$ Other factors besides the CNT itself, such as experimental conditions, have also been suggested to contribute to a misleading toxicity evaluation. ${ }^{14,30,31}$ Two recent studies by our group examined the possible factors contributing to the variable cytotoxicity of CNTs in vitro. In one study, it was found that cytotoxicity differed according to the dispersant that is used. ${ }^{32} \mathrm{CNTs}$ dispersed with gelatin or 1,2-dipalmitoyl-sn-glycero-3-phosphocholine were endocytosed and induced concentration-dependent cytotoxicity and cytokine secretion, while the same was not observed when carboxymethyl cellulose was used instead. Varying degrees of cytotoxicity were also observed in different cell lines. ${ }^{33}$ MWCNTs were endocytosed by, and were toxic to, malignant pleural mesothelioma, bronchial epithelial, and macrophage-like cells, but not neuroblastoma and monoblastic cells. Endocytosed MWCNTs accumulated in the lysosome, causing injury to the membrane. However, endocytosed carbon black, a carbon allotrope, had no cytotoxic effects despite settling in the lysosome. This indicates that the toxicity associated with CNTs, which are internalized due to their nanosize, is not an inherent property of the constituent carbon (which is considered inert), but is actually due to other factors.

In the present study, we investigated whether the physical dimensions and type of CNTs influence cellular response. MWCNTs (Showa Denko KK, Tokyo, Japan) and CSCNTs (GSI Creos, Tokyo, Japan) of various diameters and lengths were tested in two different epithelial cell lines, in which responses were evaluated based on several biological parameters. The findings indicate that the cellular response to CNTs is dependent on multiple factors, which should be considered while developing CNTs that have optimal biocompatibility.

\section{Materials and methods} CNT preparation

The properties of the MWCNTs are listed in Table 1, and those of the CSCNTs ${ }^{34}$ are listed in Table 2. Three types of MWCNTs - VGCF ${ }^{\circledR}$ X, VGCF ${ }^{\circledR}$-S, and $\mathrm{VGCF}^{\circledR}$ (vapor grown carbon fibers; with diameters of 15,80 , and $150 \mathrm{~nm}$,
Table I Properties of multi-walled carbon nanotubes (MWCNTs)

\begin{tabular}{llll}
\hline MWCNTs & VGCF $^{\circledR}$ & VGCF $^{\circledR} \mathbf{S}$ & $\mathbf{V G C F}^{\circledR} \mathbf{- X}$ \\
\hline Length $(\mu \mathrm{m})$ & 8 & 10 & 3 \\
Diameter $(\mathrm{nm})$ & $\mathrm{I} 50$ & 80 & 15 \\
Agglomeration size $(\mathrm{nm})$ & $\mathrm{I}, 660 \pm 38$ & $\mathrm{I}, 638 \pm 98$ & $4,417 \pm 40 \mathrm{I}$ \\
Iron content (ppm) & 34 & $\mathrm{I}, 700$ & 12,000 \\
\hline
\end{tabular}

Note: MWCNTs were provided by Showa Denko KK (Tokyo, Japan).

Abbreviation: VGCF, vapor grown carbon fibers.

respectively) - and three CSCNTs of different lengths (CS-L, 20-80 $\mu \mathrm{m}$; CS-S, 0.5-20 $\mu \mathrm{m}$; and CS-M, of intermediate length) were tested. The CNTs were sterilized by autoclaving at $121^{\circ} \mathrm{C}$ for 15 minutes, then dispersed in $0.1 \%$ gelatin in phosphate-buffered saline (PBS) and sonicated in a water bath for 30 minutes.

\section{Cell culture}

The BEAS-2B human bronchial epithelial cell line was purchased from the American Type Culture Collection (ATCC), (Manassas, VA, USA). The ACC-MESO-1 human malignant pleural mesothelioma cell line ${ }^{35}$ was purchased from RIKEN (Wako, Ibaraki, Japan). BEAS-2B cells were cultured in Ham's Nutrient Mixture F-12 (Nacalai Tesque) with 10\% fetal bovine serum ([FBS] Life Technologies, Carlsbad, CA, USA), and MESO- 1 cells were cultured in RPMI1640 supplemented with $10 \%$ FBS. Both cell lines were cultured at $37^{\circ} \mathrm{C}$ in a $5 \% \mathrm{CO}_{2}$ humidified incubator and passaged twice a week. For each study, cells were seeded at a density of $2 \times 10^{5}$ or $5 \times 10^{5}$ cells $/ \mathrm{mL}$ and adhered for 24 hours.

\section{alamarBlue $^{\circledR}(A B)$ assay}

To assess cell viability upon exposure to CNTs, an AB assay (Life Technologies) was performed according to the manufacturer's instructions. Cells were incubated for 24 hours at $37^{\circ} \mathrm{C}$ in culture medium with 1,10 , or $50 \mu \mathrm{g} / \mathrm{mL}$ CNTs in 96-well culture plates. Control cells were cultured in medium containing the dispersant medium $(0.001 \%$ gelatin). Viable cells metabolized the dye, resulting in an increase in fluorescence by excitation/emission at $550 / 600 \mathrm{~nm}$, which was recorded by a fluorescence multiplate reader (PowerScan 4; DS Pharma Biomedical,

Table 2 Properties of cup-stacked carbon nanotubes (CSCNTs)

\begin{tabular}{llll}
\hline CSCNTs & CS-L & CS-M $^{a}$ & CS-S \\
\hline Length $(\mu \mathrm{m})$ & $20-80$ & & $0.5-20$ \\
Diameter $(\mathrm{nm})$ & 100 & 100 & 100 \\
Agglomeration size $(\mathrm{nm})$ & $2,029 \pm 79$ & $1,833 \pm 20 \mathrm{I}$ & $1,547 \pm 15$ \\
\hline
\end{tabular}

Notes: CSCNTs were provided by GSI Creos (Tokyo, Japan). aBlank space denotes that CS-M is between CS-L and CS-S in terms of length. 
Osaka, Japan). Cytotoxic activity was calculated as follows:

Percent cytotoxicity

$=100 \times$ experimental value/control value

Each sample was assayed six times.

\section{Lactate dehydrogenase (LDH) release assay}

To determine plasma membrane permeability of cells exposed to CNTs, cells grown in 24-well plates were incubated for 24 hours at $37^{\circ} \mathrm{C}$ with or without CNT $(10 \mu \mathrm{g} / \mathrm{mL})$. LDH activity in the culture medium was measured using an LDH Cytotoxicity Assay Kit (Cayman Chemical Co, Ann Arbor, MI, USA) according to the manufacturer's instructions. The red formazan product was measured at $490 \mathrm{~nm}$ using a multiplate reader (VERSA max; Molecular Devices LLC, Sunnyvale, CA, USA). Positive control cells were cultured in medium containing $0.01 \%$ Triton X-100 and permeability was defined as $100 \%$. Experiments were performed in triplicate.

\section{Assessment of CNT uptake by laser scanning confocal microscopy (LSM)}

Cells were treated with CellLight ${ }^{\circledR}$ Lysosomes-RFP and Early Endosomes-GFP (Life Technologies) according to the manufacturer's instructions, and cultured on $\mu$-Slide 8-well chambered slides with an ibiTreat surface (ibidi $\mathrm{GmbH}$, Martinsried, Germany) for 24 hours in a $5 \% \mathrm{CO}_{2}$ incubator. After the cells were treated, they were incubated with or without CNTs $(1 \mu \mathrm{g} / \mathrm{mL}$ in BEAS-2B and $10 \mu \mathrm{g} / \mathrm{mL}$ in MESO-1 cells) for 24 hours. Before observation, the cells were stained with bisbenzimide $\mathrm{H} 33342$ fluorochrome trihydrochloride ([H33342] $1 \mu \mathrm{g} / \mathrm{mL})$ for 30 minutes. Cells were visualized with differential interference contrast optics and by fluorescence using an LSM510 NLO confocal microscope (Carl Zeiss Meditec AG, Jena, Germany) equipped with blue diode (360 nm), argon (488 nm), and helium-neon (543 nm) lasers for excitation of H33342, GFP, and RFP, respectively.

\section{Assessment of CNT uptake by transmission electron microscopy (TEM)}

Cells grown on cover slips in a $3.5 \mathrm{~cm}$ culture dish were exposed to CNTs $(1 \mu \mathrm{g} / \mathrm{mL}$ in BEAS-2B and $10 \mu \mathrm{g} / \mathrm{mL}$ in MESO-1 cells) for 24 hours. Cells were washed twice in PBS, fixed with $2.5 \%$ glutaraldehyde, postfixed with $1 \%$ osmic acid, and embedded in Epon. Sections were cut at $60 \mathrm{~nm}$, stained with uranyl acetate and lead citrate, and visualized under a JEM1400 transmission electron microscope (JEOL, Tokyo, Japan) at $80 \mathrm{keV}$.

\section{Total reactive oxygen species (ROS)/superoxide production}

Total ROS/superoxide production in cells exposed to CNTs was determined using a total ROS/superoxide detection kit (Enzo Life Sciences, Inc., Farmingdale, NY, USA) according to the manufacturer's instructions. After the cells had adhered for 24 hours in 12-well plates, they were pretreated with oxidative stress detection reagent and superoxide detection reagent for 30 minutes before CNT solution $(1 \mu \mathrm{g} / \mathrm{mL}$ in BEAS-2B and $10 \mu \mathrm{g} / \mathrm{mL}$ in MESO-1 cells) was added. Pyocyanin $(100 \mu \mathrm{M})$ was used to induce ROS production. After 60 minutes, the cells were washed once with $1 \times$ wash buffer and harvested with trypsin-ethylenediaminetetraacetic acid. Cells were resuspended in $0.3 \mathrm{~mL} 1 \times$ wash buffer with $10 \%$ FBS and passed through a nylon mesh; then, they were subjected to flow cytometry (FACSCalibur ${ }^{\mathrm{TM}}$; BD Biosciences, San Jose, CA, USA) using the FL1 and FL2 channels for oxidative stress detection reagent and superoxide detection reagent signals, respectively, until 10,000 cells were recorded. Cell suspensions were assayed in triplicate for each treatment condition.

\section{Evaluation of intracellular acidity}

To assess lysosomal acidity, ${ }^{36}$ cells were adhered in a 12 -well plate for 24 hours and exposed to CNTs ( 1 or $10 \mu \mathrm{g} / \mathrm{mL}$ in BEAS-2B and 1,10 , or $50 \mu \mathrm{g} / \mathrm{mL}$ in MESO-1 cells) for 24 hours. Cells were washed twice with PBS, and then incubated for 30 minutes under growth conditions in prewarmed medium containing $1 \mu \mathrm{M}$ LysoSensor ${ }^{\mathrm{TM}}$ Green DND-189 dye (Life Technologies). After washing with PBS, cells were resuspended in PBS containing 10\% FBS and subjected to flow cytometry until 10,000 cells were recorded. Cell suspensions were assayed in quadruplicate for each treatment condition and the LysoSensor intensity (\%) was calculated. Since CNTs may interfere with the fluorescence signal during flow cytometry, control cells that were not exposed to CNTs prior to incubation with LysoSensor were prepared as a CNT blank, and CNTs were added before resuspension. CNT blank samples were assayed and the CNT inhibition intensity (\%) was calculated. The change in $\%$ intensity was calculated as follows:

$$
\begin{aligned}
\Delta \% \text { intensity }= & \text { LysoSensor intensity }-\mathrm{CNT} \text { inhibition } \\
& \text { intensity }
\end{aligned}
$$


To obtain images of intracellular acidity levels, BEAS-2B cells treated with Lysosomes-RFP were adhered on $\mu$-Slide 8-well chambered slides for 24 hours and incubated with or without $1 \mu \mathrm{g} / \mathrm{mL}$ CNT for 24 hours. Cells were washed twice with PBS, and then incubated for 30 minutes under growth conditions in prewarmed medium containing $1 \mu \mathrm{M}$ LysoSensor dye. Cells were visualized by fluorescence microscopy (Axio Observer.Z1; Carl Zeiss) using a $40 \times$ objective.

\section{Statistical analysis}

All data are presented as mean \pm standard error. Values were obtained from at least three independent experiments. The Student's $t$-test was used to compare means, and $P<0.05$ was considered statistically significant.

\section{Results}

\section{CSCNTs have lower toxicity than MWCNTs}

The cytotoxicity of CNTs was assessed using the AB assay (Figure 1A). The toxicity of MWCNTs in BEAS-2B cells was concentration dependent, but did not vary as a function of length or diameter. The toxicity of CSCNTs in BEAS-2B cells was dependent on concentration and length (Figure 1B). In MESO-1 cells, MWCNT toxicity varied by concentration and was consistently lower than in BEAS-2B cells (Figure 1C). CSCNTs were not toxic to MESO-1 cells, except at the highest concentrations $(50 \mu \mathrm{g} / \mathrm{mL})$ of CS-L and CS-M (Figure 1D). MWCNTs were more toxic than CSCNTs in both cell lines.

\section{BEAS-2B cells are more permeable to MWCNTs than CSCNTs}

The LDH assay was used to evaluate plasma membrane permeability. BEAS-2B cells were more permeable to MWCNTs $(>50 \%)$ than CSCNTs $(<50 \%)$ at a CNT concentration of $10 \mu \mathrm{g} / \mathrm{mL}$ (Figure 2A). Among MWCNTs, permeability to VGCF-X was highest at $77 \%$, followed by VGCF-S and VGCF; for CSCNTs, permeability was CS-M $\geq$ CS-L $>$ CS-S. The permeability of MESO- 1 cells to both types of CNT was $<30 \%$, with cells being most permeable
A
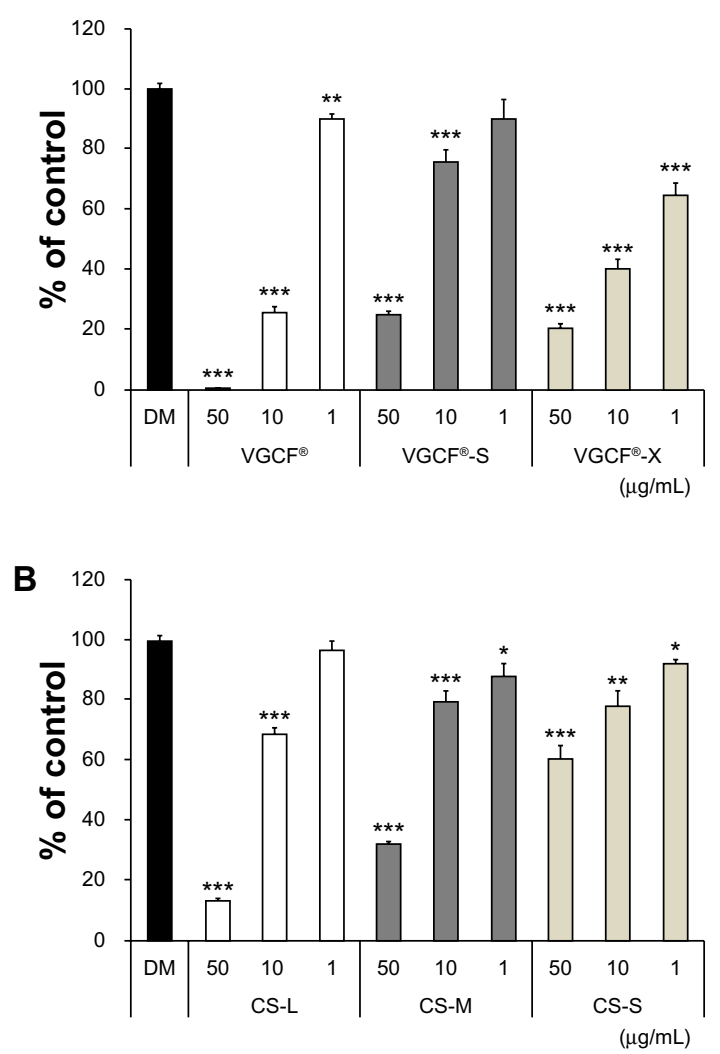

C

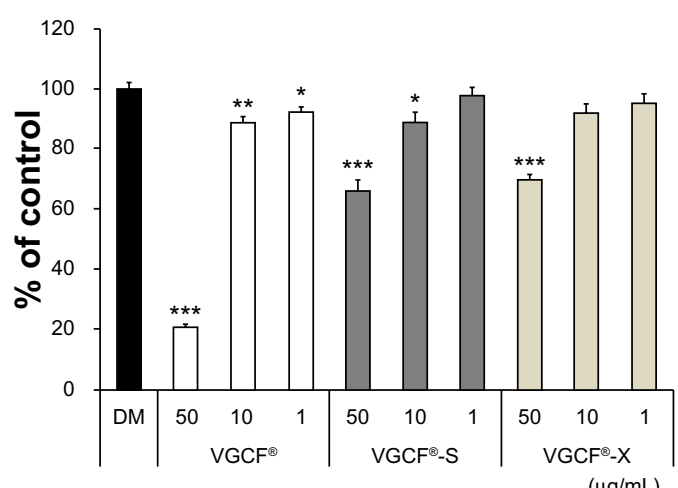

D

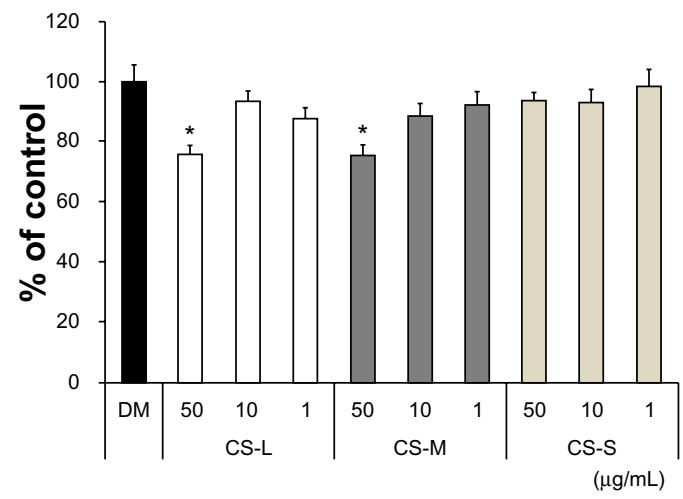

Figure I Cell viability upon exposure to CNTs.

Notes: Cells were exposed to the indicated concentrations of CNT for 24 hours. BEAS-2B cells exposed to (A) MWCNTs (VGCF ${ }^{\circledR}$-X, VGCF ${ }^{\circledR}-\mathrm{S}$, and VGCF $\left.{ }^{\circledR}\right)$ and $(\mathbf{B})$ CSCNTs (CS-L, CS-S, and CS-M). MESO-I cells exposed to (C) MWCNTs and (D) CSCNTs. DM (0.00I\% gelatin) served as the control, and data are expressed as mean \pm standard error $(n=6)$. $* P<0.05$; **P $<0.01$; *** $P<0.00$ I. MWCNTs were provided by Showa Denko KK (Tokyo, Japan); CSCNTs were provided by GSI Creos (Tokyo, Japan); VGCF, vapor grown carbon fibers; CS-L, CSCNT of length 20-80 $\mu \mathrm{m}$; CS-S, CSCNT of length 0.5-20 $\mu$ m; CS-M, CSCNT of intermediate length.

Abbreviations: CNT, carbon nanotube; CSCNT, cup-stacked CNT; DM, dispersant medium; MWCNT, multi-walled CNT; VGCF, vapor grown carbon fibers; CS-L, CSCNT of length $20-80 \mu \mathrm{m}$; CS-S, CSCNT of length $0.5-20 \mu \mathrm{m}$; CS-M, CSCNT of intermediate length. 
A

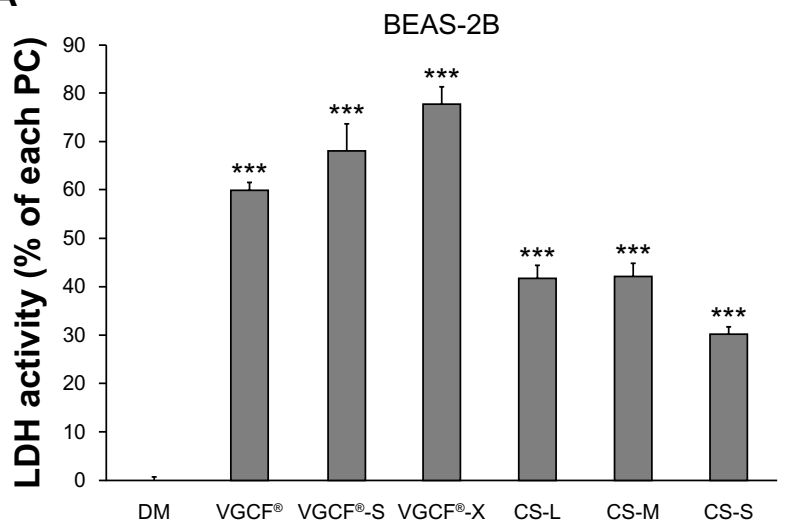

B

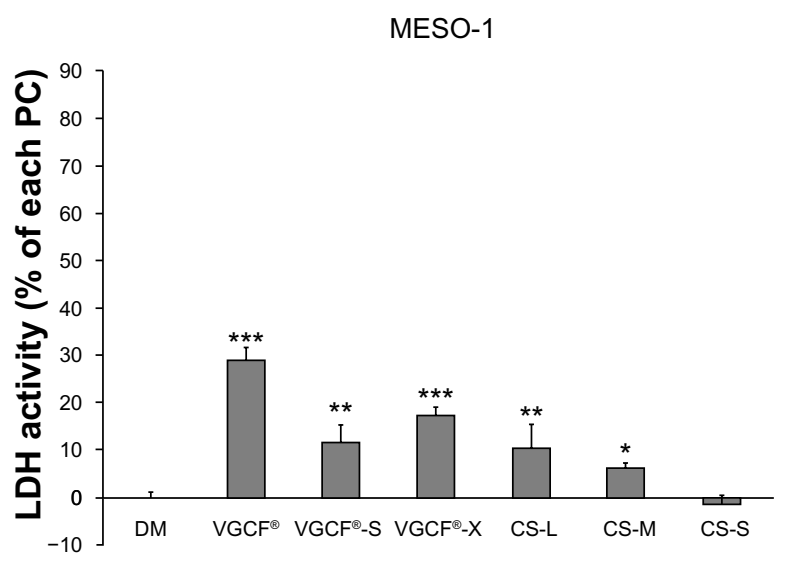

Figure 2 Plasma membrane permeability in cells exposed to CNTs.

Notes: Cells were exposed to $10 \mu \mathrm{g} / \mathrm{mL}$ CNT for 24 hours. (A) BEAS-2B and (B) MESO-I cells exposed to MWCNTs or CSCNTs. The LDH activity was calculated by the formula ([experimental value - DM value]/[PC value - DM value]) $\times 10 \times 100(\%)$. PC is $0.01 \%$ Triton $X-100$; DM is $0.001 \%$ gelatin. Data are compared to the control (DM) and expressed as mean \pm standard error $(n=3)$. $* P<0.05 ; * * P<0.01 ; * * * P<0.001$. MWCNTs were provided by Showa Denko KK (Tokyo, Japan); CSCNTs were provided by GSI Creos (Tokyo, Japan).

Abbreviations: CNT, carbon nanotube; CSCNT, cup-stacked CNT; DM, dispersant medium; LDH, lactate dehydrogenase; MWCNT, multi-walled CNT; PC, positive control; VGCF, vapor grown carbon fibers; CS-L, CSCNT of length 20-80 $\mu \mathrm{m}$; CS-S, CSCNT of length $0.5-20 \mu \mathrm{m}$; CS-M, CSCNT of intermediate length.

to VGCF at 29\% (Figure 2B). In general, permeability followed a trend that was similar, but not identical, to cytotoxicity in both cell types, with membrane permeability at $10 \mu \mathrm{g} / \mathrm{mL}$ reflecting the trend for cytotoxicity at $50 \mu \mathrm{g} / \mathrm{mL}$.

\section{MWCNTs and CSCNTs aggregate in the lysosome of BEAS-2B cells}

BEAS-2B cells that had endocytosed CNTs were observed by LSM and TEM (Figures 3A and 4A). Cells were treated with fluorescent protein-signal peptide fusion molecules to visualize the lysosome (RFP) and early endosome (GFP). GCF, VGCF-S, and CS-L were visible as multiple long fiber bundles adjacent to the nucleus and were seen protruding from the lysosome (Figure 3Ab, 3Ac, and 3Ae). Although a similar distribution of the fibers was observed with VGCF-X and CS-S, for the former, only a portion of the agglomerate was inside the lysosome while the majority of fibers penetrated the plasma membrane, as opposed to CS-S fibers, which were mostly in the lysosomal compartment (Figure 3Ad and 3Ag). CS-Ms were observed as both single fibers and aggregates and appeared as a mixture of CS-Ls and CS-Ss (Figure 3Af). There was no overlap in the signals of early endosomes and CNTs in the cytoplasm of BEAS-2B and MESO-1 cells. The lysosomal distribution of VGCF, VGCF-S, and CS-L was more clearly visible by TEM (Figure 4Ab, 4Ac and 4Ae). Two pits were observed in the process of endocytosis of VGCF-X aggregates (Figure 4Ag).

Although MESO-1 cells were exposed to MWCNTs and CSCNTs at a tenfold higher concentration than BEAS-2B cells (Figure 3B), CNT fibers and agglomerates were not specifically associated with the lysosome and were instead distributed throughout the cytoplasm while being excluded from the nucleus, with no obvious effects on adhesion or viability. In TEM images, a few isolated VGCF and VGCF-S fibers were observed adjacent to nuclei (Figure $4 \mathrm{Bb}$ and $4 \mathrm{Bc}$ ), while the other CNTs were present as aggregates (Figure $4 \mathrm{Bd}-\mathrm{g}$ ).

\section{MWCNTs stimulate ROS production in BEAS-2B cells}

The total ROS production in BEAS-2B cells exposed to MWCNTs and CSCNTs is shown in Figure 5A. Oxidative stress was significantly upregulated, and superoxide dismutase activity was slightly increased by VGCF-X compared to that for the positive control pyocyanin. An increase in oxidative stress level was observed in MESO-1 cells exposed to VGCF-X (Figure 5B).

\section{CNTs induce lysosomal acidification upon uptake}

An acidotropic probe, which accumulates in acidic organelles and exhibits $\mathrm{pH}$-dependent increases in fluorescence intensity upon acidification, was used to evaluate changes in intracellular acidity upon exposure to CNTs. Cells that had internalized CNTs were isolated by flow cytometry (Figure 6A and B). BEAS-2B cells exposed to $50 \mu \mathrm{g} / \mathrm{mL}$ MWCNTs were not analyzed because a sufficient number of living cells could not be obtained for analysis due to the toxicity of MWCNTs at this concentration. Increases in intensity upon exposure of BEAS-2B cells to $1 \mu \mathrm{g} / \mathrm{mL}$ VGCF, VGCF-S, and VGCF-X were $10.8 \%, 7.5 \%$, and $17.5 \%$, respectively, while, for CSCNTs at the same concentration, the values were $<5 \%$ (Figure $6 \mathrm{~A}$ ). However, at $10 \mu \mathrm{g} / \mathrm{mL}$, all CNTs induced increases in intensity of $>10 \%$ in BEAS-2B cells. 

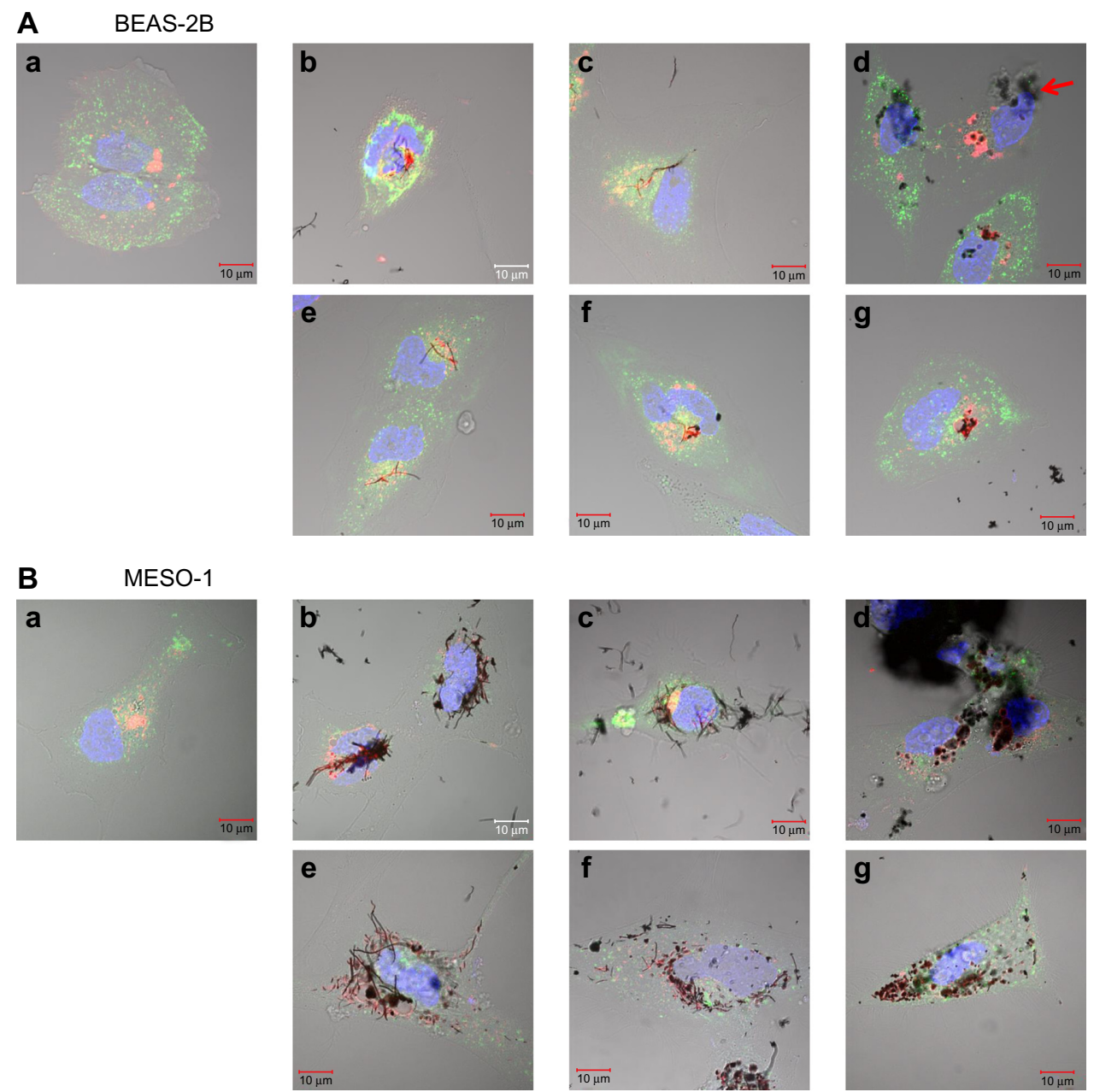

Figure 3 Live cells imaged by differential interference contrast optics after incubation with CellLight ${ }^{\circledR}$ Lysosomes-RFP and Early Endosomes-GFP (Life Technologies, Carlsbad, CA, USA) and bisbenzimide $\mathrm{H} 33342$ fluorochrome trihydrochloride for nuclear staining.

Notes: (A) BEAS-2B cells were exposed to I $\mu \mathrm{g} / \mathrm{mL}$ MWCNT (VGCF) or CSCNT (CS) for 24 hours. (a) DM (control); (b) VGCF ${ }^{\circledR}$; (c) VGCF ${ }^{\circledR}$-S; (d) VGCF ${ }^{\circledR}$-X; (e) CS-L; $(f)$ CS-M; and (g) CS-S. Red arrow indicates VGCF-X agglomerates, which were not taken up by BEAS-2B cells, nor did they fully penetrate the cell membrane. Scale bar $=10 \mu \mathrm{m}$. (B) MESO-I cells were exposed to $10 \mu \mathrm{g} / \mathrm{mL}$ MWCNT (VGCF) or CSCNT (CS) for 24 hours. (a) DM (control); (b) VGCF; (c) VGCF-S; (d) VGCF-X; (e) CS-L; (f) CS-M; and (g) CS-S. Scale bar = $10 \mu \mathrm{m}$. MWCNTs were provided by Showa Denko KK (Tokyo, Japan); CSCNTs were provided by GSI Creos (Tokyo, Japan).

Abbreviations: CSCNT, cup-stacked carbon nanotube; DM, dispersant medium; MWCNT, multi-walled carbon nanotube; CS-L, CSCNT of length 20-80 $\mu$ m; CS-S, CSCNT of length $0.5-20 \mu \mathrm{m} ; \mathrm{CS}-\mathrm{M}$, CSCNT of intermediate length.

In contrast, in MESO-1 cells, changes were mostly $\leq 10 \%$, with VGCF and VGCF-S (at $50 \mu \mathrm{g} / \mathrm{mL}$ ) accounting for more than $30 \%$ of the total increase (Figure 6B). To determine whether acidification was due to CNT uptake, the lysosomes of BEAS-2B cells exposed to $10 \mu \mathrm{g} / \mathrm{mL} \mathrm{CNT}$ and treated with the acidotropic probe were visualized, while control cells were double-stained with Lysosomes-RFP dye and emitted orange fluorescence (Figure 6C). Small vacuoles were observed in CNT-exposed cells, but CNT aggregates were visible only in lysosomes, confirming that the observed increases in intensity were due to lysosomal CNT uptake.

\section{Discussion}

A major concern for the use of CNTs is their safety, since their shape is similar to that of asbestos. Although CNTs need to be internalized by cells in order to be useful as carriers, intracellular accumulation can be cytotoxic..$^{32}$ A number of studies have investigated the biodegradability of CNTs in an attempt to address this issue. ${ }^{37-39}$ However, CNTs are inherently stable, and degradation by chemical modification has yet to be developed. Therefore, the present study examined the optimal CNT shape and size that can maximize biocompatibility using two different types of CNT.

Both BEAS-2B and MESO-1 cells internalized MWCNTs, but different cytotoxic effects were observed in each cell line. In BEAS-2B cells, toxicity varied as a function of diameter, such that the toxicity was VGCF > VGCF-X > VGCF-S, while for MESO-1 cells, the order was VGCF $>$ VGCF-S $\geq$ VGCF-X (Figure 1). In another study, macrophages, but not mesothelial or 
A

BEAS-2B
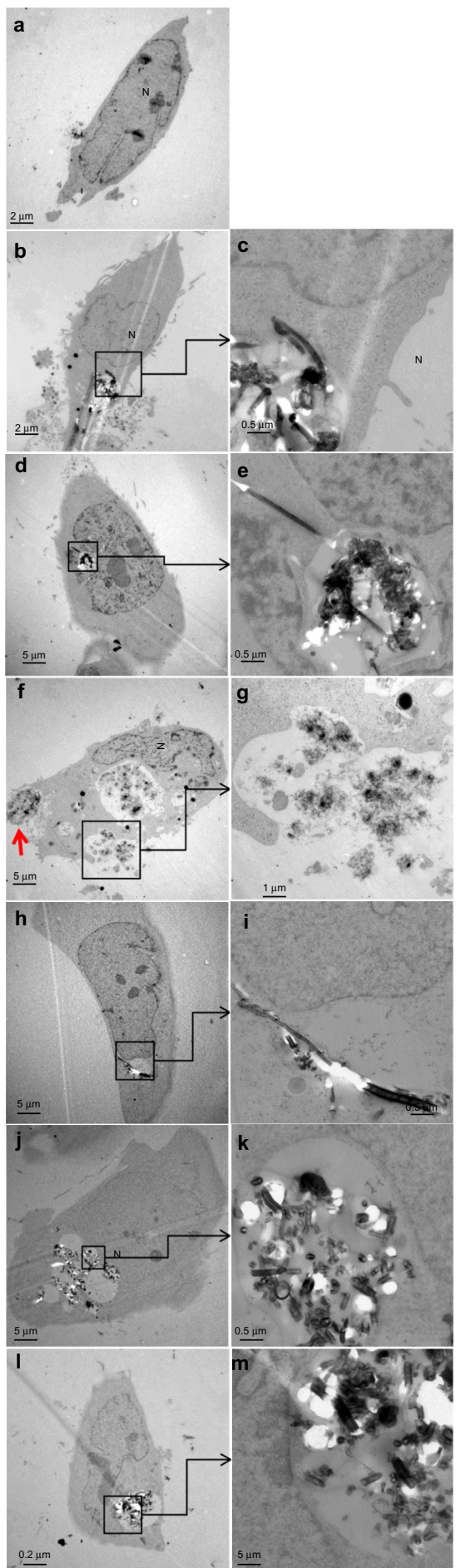

B

MESO-1

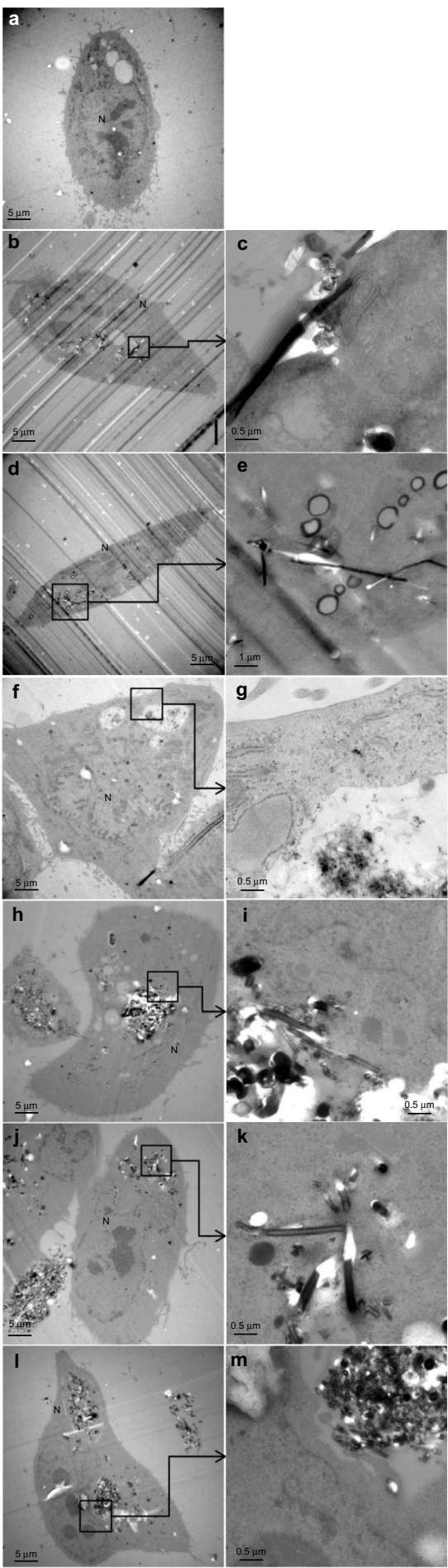

Figure 4 Transmission electron micrographs of BEAS-2B and MESO-I cells exposed to CNTs.

Notes: (A) BEAS-2B cells were exposed to I $\mu \mathrm{g} / \mathrm{mL}$ MWCNT (VGCF) or CSCNT (CS) for 24 hours. (a) DM (control); (b and c) VGCF ${ }^{\oplus}$; (d and e) VGCF ${ }^{\circledR}$; ; (f and g) VGCF ${ }^{-}$-X; ( $h$ and i) CS-L; ( $j$ and k) CS-M; and ( and $\mathrm{m}$ ) CS-S. Red arrow indicates VGCF-X agglomerates, which were not taken up by BEAS-2B cells, nor did they fully penetrate the cell membrane. (B) MESO-I cells were exposed to $10 \mu \mathrm{g} / \mathrm{mL}$ MWCNT or CSCNT for 24 hours. (a) DM (control); (b and c) VGCF; (d and e) VGCF-S; (f and g) VGCF-X; (h and i) CS-L; (j and k) CS-M; and (I and m) CS-S. MWCNTs were provided by Showa Denko KK (Tokyo, Japan); CSCNTs were provided by GSI Creos (Tokyo, Japan). Abbreviations: CNT, carbon nanotube; CSCNT, cup-stacked carbon nanotube; DM, dispersant medium; MWCNT, multi-walled carbon nanotube; CS-L, CSCNT of length 20-80 $\mu \mathrm{m}$; CS-S, CSCNT of length $0.5-20 \mu \mathrm{m}$; CS-M, CSCNT of intermediate length; VGCF, vapor grown carbon fibers. 


\section{A BEAS-2B}
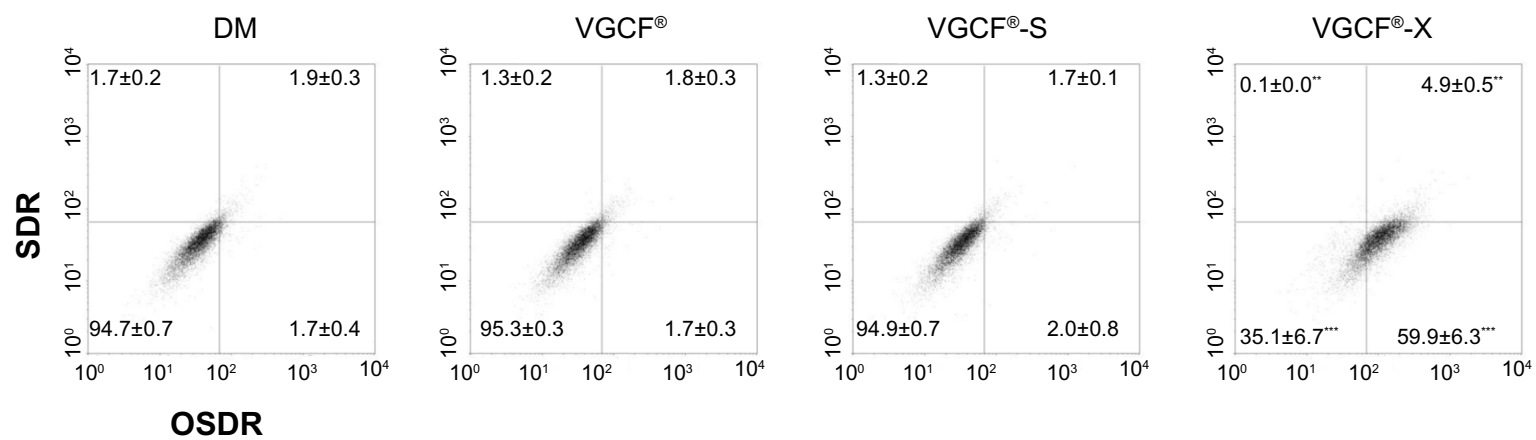

Pyocyanin

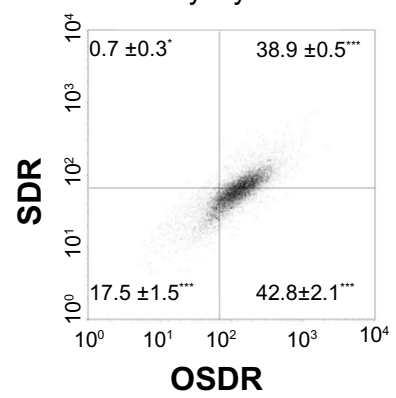

CS-L

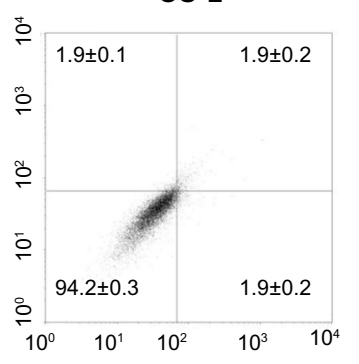

CS-M

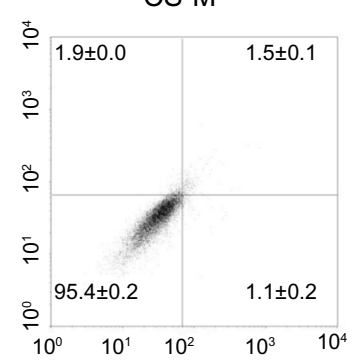

CS-S

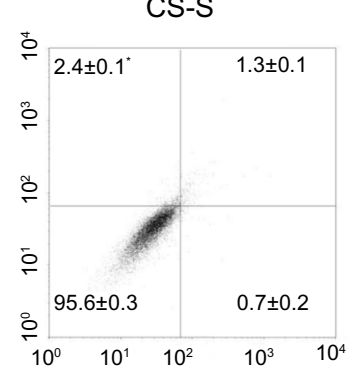

B MESO-1
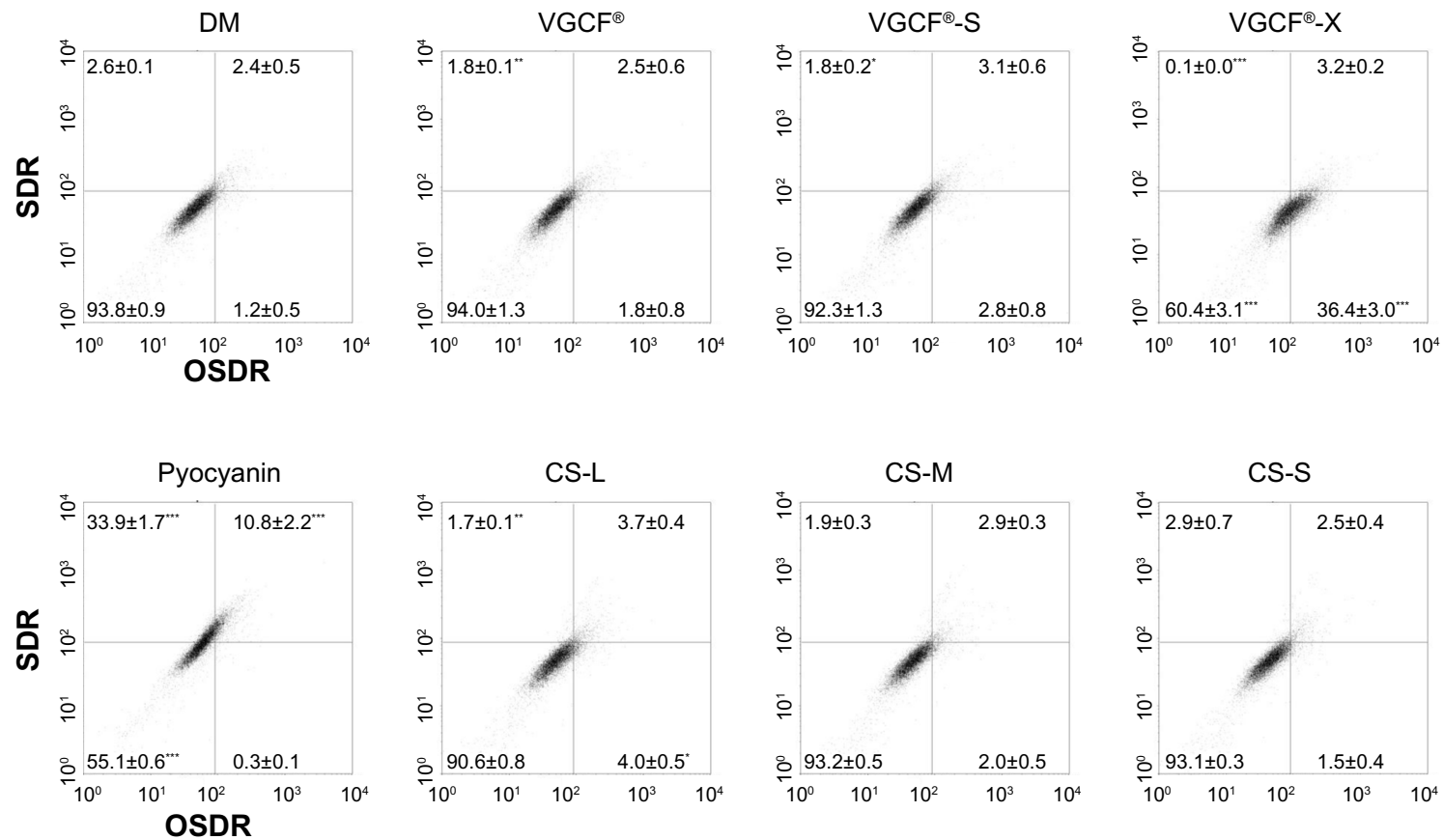

Figure 5 Total reactive oxygen species production upon exposure to CNTs.

Notes: (A) BEAS-2B cells were exposed to I $\mu \mathrm{g} / \mathrm{mL}$ MWCNT (VGCF ${ }^{\circledR}$, VGCF ${ }^{\circledR}-\mathrm{S}$, and VGCF ${ }^{\circledR}-\mathrm{X}$ ) or CSCNT (CS-L, CS-M, and CS-S) for I hour. (B) MESO-I cells were exposed to $10 \mu \mathrm{g} / \mathrm{mL}$ MWCNT (VGCF, VGCF-S, and VGCF-X) or CSCNT (CS-L, CS-M, and CS-S) for I hour. Pyocyanin (I00 $\mu M$ ) was used to induce the production of reactive oxygen species. Data are expressed as mean \pm standard error $(n=3)$. $* P<0.05 ; * * P<0.01 ; * * * P<0.001$. MWCNTs were provided by Showa Denko KK (Tokyo, Japan); CSCNTs were provided by GSI Creos (Tokyo, Japan).

Abbreviations: CNT, carbon nanotube; CSCNT, cup-stacked carbon nanotube; DM, dispersant medium; MWCNT, multi-walled carbon nanotube; OSDR, oxidative stress detection reagent; SDR, superoxide detection reagent; CS-L, CSCNT of length 20-80 $\mu \mathrm{m}$; CS-S, CSCNT of length 0.5-20 $\mu \mathrm{m}$; CS-M, CSCNT of intermediate length; VGCF, vapor grown carbon fibers. 
A

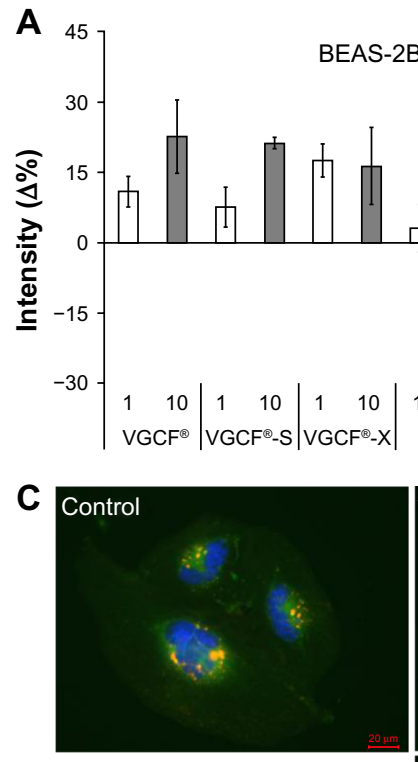

B
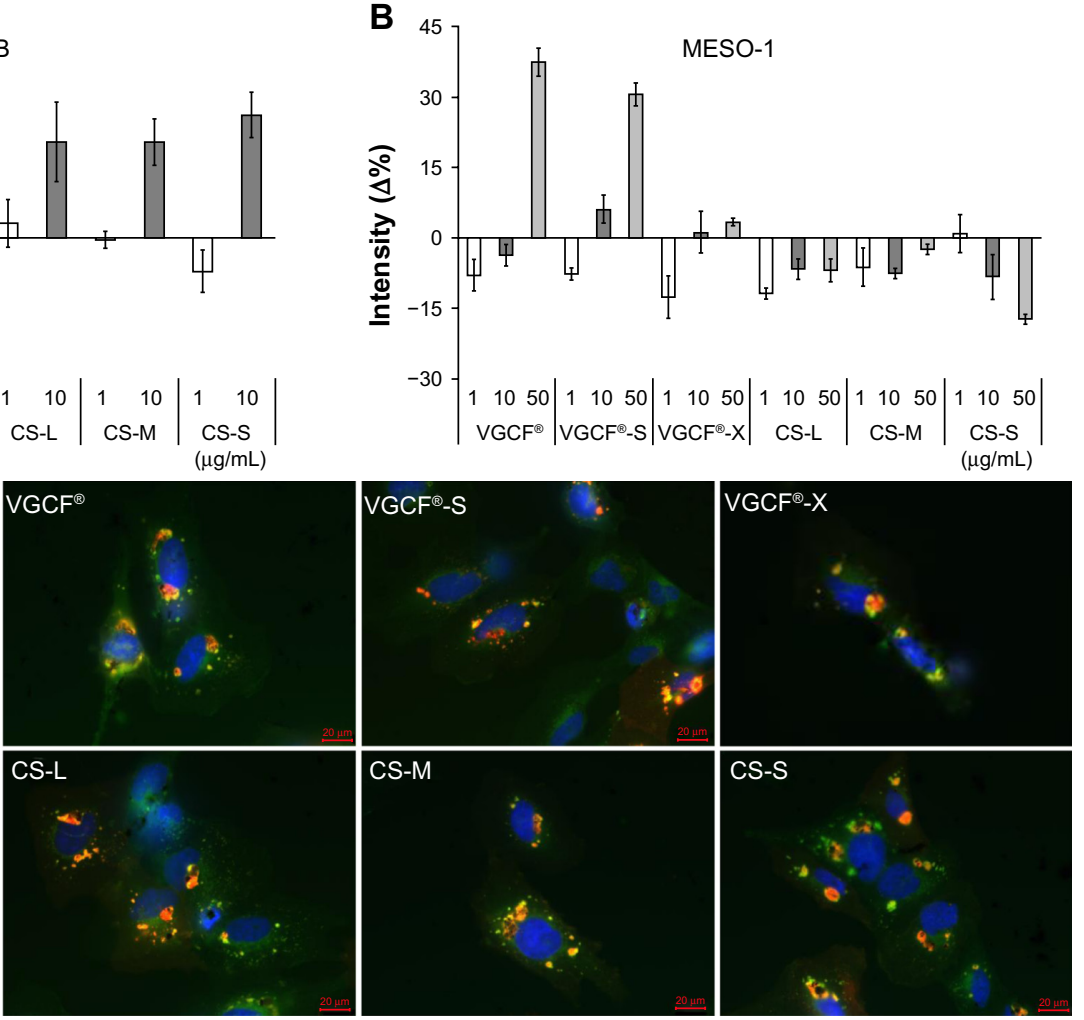

Figure 6 Intracellular acidification upon exposure to CNTs.

Notes: (A) BEAS-2B cells were exposed to I and $10 \mu \mathrm{g} / \mathrm{mL}$ of MWCNT (VGCF ${ }^{\circledR}-\mathrm{X}, \mathrm{VGCF}^{\circledR}-\mathrm{S}$, and VGCF ${ }^{\circledR}$ ) or CSCNT (CS-L, CS-S, and CS-M) for 24 hours. (B) MESO-I cells were exposed to I, 10, and $50 \mu \mathrm{g} / \mathrm{mL}$ MWCNT or CSCNT for 24 hours, incubated with an acidotropic probe (LysoSensor TM; Life Technologies, Carlsbad, CA, USA), and analyzed by flow cytometry (I0,000 cells). The LysoSensor intensity (\%) was calculated as follows: ([FLI channel intensity of cells exposed to CNTs - FLI channel intensity of untreated cells]/[FLI channel intensity of cells exposed to DM - FLI channel intensity of untreated cells]) $\times 100 \%$. DM is $0.001 \%$ gelatin. CNT inhibition intensity (\%) was calculated as follows: ([FLI channel intensity of CNT blank - FLI channel intensity of untreated cells]/[FLI channel intensity of DM blank - FLI channel intensity of untreated cells]) $\times 100 \%$. The intensity change was determined as follows: intensity $(\Delta \%)=$ LysoSensor intensity (\%) $-\mathrm{CNT}$ inhibition intensity (\%). Data are expressed as mean \pm standard error $(\mathrm{n}=4)$. (C) BEAS-2B cells were exposed to $10 \mu \mathrm{g} / \mathrm{mL}$ MWCNT (VGCF, VGCF-S, and VGCF-X) or CSCNT (CS-L, CS-M, and CS-S) for 24 hours and visualized by staining with LysoSensor dye (green), CellLight ${ }^{\circledR}$ Lysosomes-RFP (red [Life Technologies]), and bisbenzimide H33342 fluorochrome trihydrochloride (blue [Nacalai Tesque, Kyoto, Japan]) for nuclei. Scale bar =20 $\mu \mathrm{m}$. MWCNTs were provided by Showa Denko KK (Tokyo, Japan); CSCNTs were provided by GSI Creos (Tokyo, Japan).

Abbreviations: CNT, carbon nanotube; CSCNT, cup-stacked carbon nanotube; DM, dispersant medium; MWCNT, multi-walled carbon nanotube; CS-L, CSCNT of length 20-80 $\mu \mathrm{m}$; CS-S, CSCNT of length 0.5-20 $\mu \mathrm{m}$; CS-M, CSCNT of intermediate length; VGCF, vapor grown carbon fibers.

epithelial cells, were shown to take up MWCNTs, whereas cytotoxicity was comparable to what was observed in BEAS-2B cells or MESO- 1 cells in the present study. ${ }^{8}$ The discordance between those results and ours may be the difference in internalization time. The previous study evaluated CNT uptake after 3 hours of MWCNT exposure, and evaluated cytotoxicity on the fourth day. Cellular uptake is dependent on time and cell type, and therefore a 3-hour exposure may be too short to evaluate the full extent of endocytosis. ${ }^{14,32}$ In contrast, CSCNTs were not toxic to MESO-1 cells; however, in BEAS-2B cells, toxicity was also dependent on size (in this case, length), with toxicity values of $\mathrm{CS}-\mathrm{L} \geq \mathrm{CS}-\mathrm{M}>\mathrm{CS}-\mathrm{S}$ (Figure 1). These results are consistent with reports that have demonstrated a positive association between CNT length and cytotoxicity. ${ }^{5,40,41}$ Although the cytotoxicity of CSCNTs of a given diameter was comparable between cell lines, VGCF-X, which is shorter than VGCF-S, was more toxic to BEAS-2B cells. VGCF-X had the shortest length and smallest diameter among the CNTs tested in this study. However, VGCF-X agglomerates had the largest diameter, and, as such, were not taken up by BEAS-2B cells, nor did they fully penetrate the cell membrane (Figures 3d and 4f). We previously reported that the volume of BEAS-2B cells is less than half of that of MESO-1 cells. ${ }^{32}$ Smaller cells may be more susceptible to cytotoxicity because of incomplete endocytosis of a CNT aggregate. This is supported by the observation that LDH activity was highest in BEAS-2B cells exposed to VGCF-X. Moreover, the fact that CS-L and CS-M induced cytotoxicity to a comparable or lesser degree than VGCF despite their greater lengths could indicate that cytotoxicity is related to CNT rigidity, which has been previously suggested. ${ }^{8}$ Although CSCNTs were similar in diameter to VGCF-S, they have greater flexibility, which predisposes them to 
becoming more easily tangled. Indeed, CS-M and CS-S appeared to be tangled inside lysosomes in the TEM and LSM images (Figures 3 and 4). Furthermore, CS-L and VGCF-S aggregates have similar shape (Figure 3) and comparable cytotoxicity values. These results demonstrate that CNT toxicity is a function not only of tube length and rigidity, but also cell and aggregate sizes, and it is therefore imprudent to make generalizations about toxicity without considering multiple parameters.

VGCF-X was the only CNT that caused an increase in total ROS (Figure 5). This indicates that CNTs are not, in general, inducers of oxidative stress in cells. It was recently shown that CNTs can act as $\mathrm{OH}$ radical scavengers. ${ }^{12,42-44}$ However, VGCF-X has a higher iron content than VGCF or VGCF-S, since it was not subjected to iron removal heat treatment, and iron is a potential source of ROS. Nonetheless, stimulation of intracellular total ROS production did not directly contribute to cytotoxicity in MESO-1 cells.

We speculated that damage to the lysosome could be the cause of cytotoxicity. In fact, non-aggregated VGCF and VGCF-S penetrated the lysosomal membrane, as seen in the TEM images (Figure 4Ac and e and 4Bc and e). Despite this, the signal intensity of injured, fluorescently labeled lysosomes remained unchanged. We recently reported that highly purified MWCNTs induced the expression of the autophagic marker light chain 3B, and 3-MA - a widely used inhibitor of autophagosome formation - reduced MWCNT-induced cytotoxicity in BEAS-2B cells. ${ }^{45}$ This was further validated by the present observation that cells exposed to CNTs showed increased acidification as a result of autophagy. ${ }^{46}$ Intracellular acidification was observed in MESO-1 cells only when exposed to VGCF and VGCF-S at a concentration of $50 \mu \mathrm{g} / \mathrm{mL}$, whereas VGCF-X used at the same concentration did not have this effect while inducing a comparable degree of cytotoxicity as VGCF-S. This study was unable to clarify how autophagy was triggered. However, since acidification was unlikely to occur in lysosomes that had endocytosed CS-S, as in the case of carbon black (reported in our previous study), ${ }^{33}$ it is probable that the shape and size of CNTs are involved in promoting autophagy.

\section{Conclusion}

The cellular response to different types of CNTs of various dimensions was evaluated. CSCNTs, with their larger surface area, are more useful for functionalization, and the length can be adjusted by ball milling. ${ }^{34,47}$ CSCNTs were also more biocompatible than MWCNTs, and therefore have greater potential as a nanobiomaterial, despite being slightly toxic. The cytotoxicity of both CNTs was dependent on many factors, including CNT shape (length, diameter, and aggregation), but also varied according to cell type. Therefore, it is necessary to confirm biocompatibility in each target cell type when considering the use of CNTs as a nanobiomaterial.

\section{Acknowledgments}

The authors thank the staff at the Division of Instrumental Analysis in the Research Center for Human and Environmental Sciences of Shinshu University for their assistance. This research was supported by the Regional Innovation Cluster Program (second stage) of the Ministry of Education, Culture, Sports, Science, and Technology of Japan; JSPS KAKENHI grant numbers 24241045, 25350524, and 25462365; Research and Development of Nanodevices for Practical Utilization of Nanotechnology of the New Energy and Industrial Technology Development Organization, Japan; the Japan Regional Innovation Strategy Program by the Excellence of the Japan Science and Technology Agency; the Adaptable and Seamless Technology Transfer Program through Target-driven R\&D; and the Hospital-Company Collaboration Support Project for Developing/Improving Problem-Solving-Type Medical Equipment by the Ministry of Economy, Trade, and Industry, Japan.

\section{Disclosure}

The authors report no conflicts of interest in this work.

\section{References}

1. Saito N, Usui Y, Aoki K, et al. Carbon nanotubes: biomaterial applications. Chem Soc Rev. 2009;38(7):1897-1903.

2. Li X, Fan Y, Watari F. Current investigations into carbon nanotubes for biomedical application. Biomed Mater. 2010;5(2):22001.

3. Adams D, Williams DF. The response of bone to carbon - carbon composites. Biomaterials. 1984;5(2):59-64.

4. Bokros JC. Carbon biomedical devices. Carbon. 1977;15(6): 353-371.

5. Poland CA, Duffin R, Kinloch I, et al. Carbon nanotubes introduced into the abdominal cavity of mice show asbestos-like pathogenicity in a pilot study. Nat Nanotechnol. 2008;3(7):423-428.

6. Takagi A, Hirose A, Nishimura T, et al. Induction of mesothelioma in p53 \pm mouse by intraperitoneal application of multi-wall carbon nanotube. J Toxicol Sci. 2008;33(1):105-116.

7. Sakamoto Y, Nakae D, Fukumori N, et al. Induction of mesothelioma by a single intrascrotal administration of multi-wall carbon nanotube in intact male Fischer 344 rats. J Toxicol Sci. 2009;34(1):65-76.

8. Nagai $\mathrm{H}$, Okazaki Y, Chew $\mathrm{SH}$, et al. Diameter and rigidity of multiwalled carbon nanotubes are critical factors in mesothelial injury and carcinogenesis. Proc Natl Acad Sci U S A. 011;108(49):E1330-E1338.

9. Kobayashi N, Naya M, Ema M, et al. Biological response and morphological assessment of individually dispersed multi-wall carbon nanotubes in the lung after intratracheal instillation in rats. Toxicology. 2010;276(3):143-153. 
10. Ellinger-Ziegelbauer H, Pauluhn J. Pulmonary toxicity of multi-walled carbon nanotubes (Baytubes) relative to alpha-quartz following a single $6 \mathrm{~h}$ inhalation exposure of rats and a 3 months post-exposure period. Toxicology. 2009;266(1-3):16-29.

11. Ma-Hock L, Treumann S, Strauss V, et al. Inhalation toxicity of multiwall carbon nanotubes in rats exposed for 3 months. Toxicol Sci. 2009;112(2):468-481.

12. Porter DW, Hubbs AF, Mercer RR, et al. Mouse pulmonary dose- and time course-responses induced by exposure to multi-walled carbon nanotubes. Toxicology. 2010;269(2-3):136-147.

13. Muller J, Delos M, Panin N, Rabolli V, Huaux F, Lison D. Absence of carcinogenic response to multiwall carbon nanotubes in a 2-year bioassay in the peritoneal cavity of the rat. Toxicol Sci. 2009;110(2): 442-448.

14. Hirano S, Fujitani Y, Furuyama A, Kanno S. Uptake and cytotoxic effects of multi-walled carbon nanotubes in human bronchial epithelial cells. Toxicol Appl Pharmacol. 2010;249(1):8-15.

15. Tabet L, Bussy C, Amara N, et al. Adverse effects of industrial multiwalled carbon nanotubes on human pulmonary cells. $J$ Toxicol Environ Health A. 2009;72(2):60-73.

16. Jacobsen NR, Pojana G, White P, et al. Genotoxicity, cytotoxicity, and reactive oxygen species induced by single-walled carbon nanotubes and $\mathrm{C}(60)$ fullerenes in the FE1-Mutatrade markMouse lung epithelial cells. Environ Mol Mutagen. 2008;49(6):476-487.

17. Monteiro-Riviere NA, Nemanich RJ, Inman AO, Wang YY, Riviere JE Multi-walled carbon nanotube interactions with human epidermal keratinocytes. Toxicol Lett. 2005;155(3):377-384.

18. Yang H, Liu C, Yang D, Zhang H, Xi Z. Comparative study of cytotoxicity, oxidative stress and genotoxicity induced by four typical nanomaterials: the role of particle size, shape and composition. J Appl Toxicol. 2009;29(1):69-78.

19. Davoren M, Herzog E, Casey A, et al. In vitro toxicity evaluation of single walled carbon nanotubes on human A549 lung cells. Toxicol In Vitro. 2007;21(3):438-448.

20. De Nicola M, Gattia DM, Bellucci S, et al. Effect of different carbon nanotubes on cell viability and proliferation. J Phys Condens Matter. 2007;19(39):395013-395019.

21. Magrez A, Kasas S, Salicio V, et al. Cellular toxicity of carbon-based nanomaterials. Nano Lett. 2006;6(6):1121-1125.

22. Wick P, Manser P, Limbach LK, et al. The degree and kind of agglomeration affect carbon nanotube cytotoxicity. Toxicol Lett. 2007;168(2): 121-131.

23. Coccini T, Roda E, Sarigiannis DA, et al. Effects of water-soluble functionalized multi-walled carbon nanotubes examined by different cytotoxicity methods in human astrocyte D384 and lung A549 cells. Toxicology. 2010;269(1):41-53.

24. Muller J, Huaux F, Fonseca A, et al. Structural defects play a major role in the acute lung toxicity of multiwall carbon nanotubes: toxicological aspects. Chem Res Toxicol. 2008;21(9):1698-1705.

25. Sato Y, Yokoyama A, Shibata K, et al. Influence of length on cytotoxicity of multi-walled carbon nanotubes against human acute monocytic leukemia cell line THP-1 in vitro and subcutaneous tissue of rats in vivo. Mol Biosyst. 2005;1(2):176-182.

26. Bottini M, Bruckner S, Nika K, et al. Multi-walled carbon nanotubes induce T lymphocyte apoptosis. Toxicol Lett. 2006;160(2):121-126.

27. Kolosnjaj-Tabi J, Hartman KB, Boudjemaa S, et al. In vivo behavior of large doses of ultrashort and full-length single-walled carbon nanotubes after oral and intraperitoneal administration to Swiss mice. ACS Nano. 2010;4(3):1481-1492.

28. Pulskamp K, Diabaté S, Krug HF. Carbon nanotubes show no sign of acute toxicity but induce intracellular reactive oxygen species in dependence on contaminants. Toxicol Lett. 2007;168(1):58-74.
29. Kagan VE, Tyurina YY, Tyurin VA, et al. Direct and indirect effects of single walled carbon nanotubes on RAW 264.7 macrophages: role of iron. Toxicol Lett. 2006;165(1):88-100.

30. Ge C, Du J, Zhao L, et al. Binding of blood proteins to carbon nanotubes reduces cytotoxicity. Proc Natl Acad Sci U S A. 2011;108(41): 16968-16973.

31. Kim JS, Song KS, Lee JH, Yu IJ. Evaluation of biocompatible dispersants for carbon nanotube toxicity tests. Arch Toxicol. 2011;85(12): 1499-1508.

32. Haniu H, Saito N, Matsuda Y, et al. Effect of dispersants of multi-walled carbon nanotubes on cellular uptake and biological responses. Int $J$ Nanomedicine. 2011;6:3295-3307.

33. Haniu H, Saito N, Matsuda Y, et al. Elucidation mechanism of different biological responses to multi-walled carbon nanotubes using four cell lines. Int J Nanomedicine. 2011;6:3487-3497.

34. Kim YA, Hayashi T, Fukai Y, Endo M, Yanagisawa T, Dresselhaus MS. Effect of ball milling on morphology of cup-stacked carbon nanotubes. Chem Phys Lett. 2002;355(3-4):279-284.

35. Usami N, Fukui T, Kondo M, et al. Establishment and characterization of four malignant pleural mesothelioma cell lines from Japanese patients. Cancer Sci. 2006;97(5):387-394.

36. Ma X, Wu Y, Jin S, et al. Gold nanoparticles induce autophagosome accumulation through size-dependent nanoparticle uptake and lysosome impairment. ACS Nano. 2011;5(11):8629-8639.

37. Allen BL, Kichambare PD, Gou P, et al. Biodegradation of singlewalled carbon nanotubes through enzymatic catalysis. Nano Lett. 2008;8(11):3899-3903.

38. Kagan VE, Konduru NV, Feng W, et al. Carbon nanotubes degraded by neutrophil myeloperoxidase induce less pulmonary inflammation. Nat Nanotechnol. 2010;5(5):354-359.

39. Sato Y, Yokoyama A, Nodasaka Y, et al. Long-term biopersistence of tangled oxidized carbon nanotubes inside and outside macrophages in rat subcutaneous tissue. Sci Rep. 2013;3:2516.

40. Murphy FA, Schinwald A, Poland CA, Donaldson K. The mechanism of pleural inflammation by long carbon nanotubes: interaction of long fibres with macrophages stimulates them to amplify pro-inflammatory responses in mesothelial cells. Part Fibre Toxicol. 2012;9:8.

41. Liu D, Wang L, Wang Z, Cuschieri A. Different cellular response mechanisms contribute to the length-dependent cytotoxicity of multiwalled carbon nanotubes. Nanoscale Res Lett. 2012;7(1):361.

42. Fenoglio I, Aldieri E, Gazzano E, et al. Thickness of multiwalled carbon nanotubes affects their lung toxicity. Chem Res Toxicol. 2012;25(1): 74-82.

43. Fenoglio I, Tomatis M, Lison D, et al. Reactivity of carbon nanotubes: free radical generation or scavenging activity? Free Radic Biol Med. 2006;40(7):1227-1233.

44. Fenoglio I, Greco G, Tomatis M, et al. Structural defects play a major role in the acute lung toxicity of multiwall carbon nanotubes: physicochemical aspects. Chem Res Toxicol. 2008;21(9): 1690-1697.

45. Tsukahara T, Matsuda Y, Usui Y, Haniu H. Highly purified, multi-wall carbon nanotubes induce light-chain 3B expression in human lung cells. Biochem Biophys Res Commun. 2013;440(2):348-353.

46. Klionsky DJ, Emr SD. Autophagy as a regulated pathway of cellular degradation. Science. 2000;290(5497):1717-1721.

47. Endo M, Kim YA, Ezaka M, et al. Selective and efficient impregnation of metal nanoparticles on cup-stacked-type carbon nanofibers. Nano Lett. 2003;3:723-726 


\section{Publish your work in this journal}

The International Journal of Nanomedicine is an international, peerreviewed journal focusing on the application of nanotechnology in diagnostics, therapeutics, and drug delivery systems throughout the biomedical field. This journal is indexed on PubMed Central, MedLine, CAS, SciSearch $\AA$, Current Contents ${ }^{\circledR} /$ Clinical Medicine,

Journal Citation Reports/Science Edition, EMBase, Scopus and the Elsevier Bibliographic databases. The manuscript management system is completely online and includes a very quick and fair peer-review system, which is all easy to use. Visit http://www.dovepress.com/ testimonials.php to read real quotes from published authors.

Submit your manuscript here: http://www.dovepress.com/international-journal-of-nanomedicine-journal 